\title{
Relationship between the agonist activity of synthetic ligands of TRAIL-R2 and their cell surface binding modes
}

\author{
Neila Chekkat ${ }^{1}$, Caterina M. Lombardo ${ }^{2,3}$, Cendrine Seguin ${ }^{1}$, Marie-Charlotte \\ Lechner $^{2,3}$, Florent Dufour ${ }^{4}$, Yves Nominé ${ }^{6,7}$, Marcella De Giorgi ${ }^{1}$, Benoit Frisch ${ }^{1,5}$, \\ Olivier Micheau ${ }^{4}$, Gilles Guichard ${ }^{2,3}$, Danièle Altschuh ${ }^{6,7, *}$ and Sylvie Fournel ${ }^{1, *}$ \\ ${ }^{1}$ Laboratoire de Conception et Application de Molécules Bioactives, UMR 7199 CNRS, Université de Strasbourg, 67401 \\ Illkirch, France \\ ${ }^{2}$ Université de Bordeaux, CBMN, UMR 5248, Institut Européen de Chimie et Biologie, 33607 Pessac, France \\ ${ }^{3}$ CNRS, CBMN, UMR 5248, 33600 Pessac, France \\ ${ }^{4}$ Centre de Recherche Lipide, Nutrition et Cancer, UMR1231 Inserm, Université de Bourgogne Franche-Comté, UFR des \\ Sciences de Santé, F21000 Dijon, France \\ ${ }^{5}$ International Center of Frontier Research in Chemistry, F67083 Strasbourg, France \\ ${ }^{6}$ Equipe labellisée Ligue 2015, UMR 7242, Université de Strasbourg, CNRS, ESBS, 67412 Illkirch, France \\ ${ }^{7}$ Present address : Institut de Génétique et de Biologie Moléculaire et Cellulaire (IGBMC), INSERM U964, CNRS UMR 7104, \\ Université de Strasbourg, 67404 Illkirch, France \\ * Co-last authors \\ Correspondence to: Sylvie Fournel, email: s.fournel@unistra.fr \\ Danièle Altschuh, email: altschud@igbmc.fr \\ Keywords: TRAIL-R2; signaling; interactions; binding modes; agonist peptides \\ Received: January 13, 2016 Accepted: February 12, 2018 Epub: February 17, 2018 Published: March 20, 2018 \\ Copyright: Chekkat et al. This is an open-access article distributed under the terms of the Creative Commons Attribution License \\ 3.0 (CC BY 3.0), which permits unrestricted use, distribution, and reproduction in any medium, provided the original author and \\ source are credited.
}

\section{ABSTRACT}

Tumor Necrosis Factor Receptor Apoptosis Inducing Ligand (TRAIL) appears as an interesting candidate for targeted cancer therapy as it induces apoptosis in cancer cells without toxicity to normal cells. TRAIL elicits apoptosis through agonist death receptor TRAIL-R1 and TRAIL-R2 engagement. Nevertheless, recombinant soluble TRAIL and monoclonal antibodies against these receptors demonstrated insufficient efficacy in clinical trials. This may be explained by the cell-type dependency of the apoptotic response, itself influenced by the effect on ligand binding mode of factors such as the level of receptor oligomerization or glycosylation. To investigate the relation between binding mode and signaling, we used previously described synthetic divalent and monovalent peptides specific for TRAIL-R2. We measured their pro-apoptotic activity on three cancer cell lines sensitive to rhTRAIL induced-apoptosis and monitored their cell-surface binding kinetics. The two divalent peptides bound with strong affinity to TRAIL-R2 expressed on B lymphoma BJAB cells and induced a high degree of apoptosis. By contrast, the same peptides bound weakly to TRAIL-R2 expressed at the surface of the human colon cancer HCT116 or T lymphoma Jurkat cell lines and did not induce their apoptosis. Cross-linking experiments suggest that these differences could be afforded by variations in the TRAIL-R2 oligomerization state at cell surface before ligand addition. Moreover divalent peptides showed a different efficiency in BJAB apoptosis induction, and kinetic distribution analysis of the BJAB binding curves suggested subtle differences in binding mechanisms. Thus our data support a relation between the cell-surface binding mode of the peptides and their pro-apoptotic activity. In this case the precise characterization of ligand binding to the surface of living cells would be predictive of the therapeutic potential of TRAIL-R2 synthetic ligands prior to clinical trials. 


\section{INTRODUCTION}

Tumor Necrosis Factor Receptor Apoptosis Inducing Ligand (TRAIL, TNFSF10) is a type 2 transmembrane protein that binds to two agonist death receptors TRAIL-R1 (DR4, TNFR-SF10A) [1] and TRAIL-R2 (DR5, TNFRSF10B) [2], as well as two decoy receptors TRAIL-R3 (DcR1，TNFR-SF10C) [3], and TRAIL-R4 (DcR2, TNFR-SF10D) [4]. TRAIL-R1/TRAIL-R2 receptors are type I transmembrane proteins that trigger apoptosis via their death domain in their intracellular region. TRAIL forms a homotrimeric ligand, that can be expressed at the membrane surface or cleaved by metalloproteases to form a soluble ligand. When bound to TRAIL-R1 or TRAIL-R2 at the cell surface, TRAIL enables the recruitment of the cytosolic protein FADD (Fas-Associated protein with Death Domain) to the receptors, which, in turn, recruit pro-caspase-8 [5]. The formed complex is called the Death Inducing Signaling Complex (DISC). After its activation in the DISC, caspase- 8 cleaves and activates the executioner caspases leading to apoptosis through the extrinsic pathway. Depending on the cell type, caspase- 8 can also cleave the pro-apoptotic protein Bid to induce the intrinsic pathway of apoptosis [6]. One important event in the TRAIL signaling pathway is the formation of a productive molecular complex between TRAIL and its agonist receptors at the membrane level [7]. Indeed, the valence and the affinity of this interaction are determinant to trigger an efficient apoptotic signal $[8,9]$. Although the clustering of multiple TRAIL-R1 or TRAIL-R2 receptors induced by the trimeric ligand is not fully understood in terms of preorganization of the receptors prior to ligand binding $[10,11]$, of kinetics of the oligomerization process [12] and of the number of receptors required for optimal signal transduction $[11,13]$, it is commonly accepted that TRAIL-R2 requires a higher degree of oligomerization as compared to TRAIL-R1 [9].

TRAIL/TRAIL-Rs appear as promising targets for cancer therapy. Indeed TRAIL induces apoptosis in cancer cells while sparing the normal ones [14]. Thus, trimeric recombinant human TRAIL (rhTRAIL) and monoclonal antibodies $(\mathrm{mAb})$ directed against TRAIL-R1 or TRAIL-R2 were developed for clinical treatment and demonstrated efficient anticancer activities in a number of preclinical studies [15]. Despite their promising potential, the first results from clinical trials are quite disappointing [16, 17], as TRAIL monotherapy generally did not induce cancer elimination. The assumption most often put forward is the acquired resistance to TRAILinduced apoptosis of tumor cells [16]. Many mechanisms have been described, that can occur at any level of the TRAIL signaling pathway (reviewed in [18, 19]). A welldescribed mechanism involves the over-expression of anti-apoptotic molecules such as c-FLIP (Cellular FLICE (FADD-like IL-1 $\beta$-converting enzyme)-inhibitory protein) as well as overexpression of proteins belonging to the Bcl-
2 family or Inhibitory of Apoptosis Protein (IAP) family. Moreover, resistance can also occur at the cell membrane level, due to mutated TRAIL-R1/R2 receptors or because of the expression of the decoy receptors TRAIL-R3 or TRAIL-R4. It was first suggested that decoy receptors could be over-expressed on some cancer cell lines leading to apoptosis resistance. Although some studies confirm this hypothesis $[20,21]$, others emphasize the lack of correlation between decoy receptor expression and TRAIL-induced apoptosis resistance [22]. However, it was recently described that while TRAIL-R3 acts as competitor for the apoptotic receptors, the TRAIL-R4 decoy receptor can form heterodimers with TRAIL-R1 or TRAIL-R2 thus preventing apoptosis induction and leading to the activation of proliferative pathways such as NFkB or Akt [23, 24]. Finally, the mechanism of apoptosis resistance proposed to explain the poor efficiency of some mAbs, was an inefficient receptor clustering thus limiting DISC formation and apoptosis [25, 26]. Indeed, it was shown that some anti-TRAIL-R2 antibodies did not induce a sufficient degree of TRAIL-R2 oligomerization to trigger apoptosis and that the cross-linking of these antibodies was required to induce optimal apoptosis in vitro $[9,27]$. To further investigate the mechanism of resistance, it seems crucial to characterize in detail the interaction between the various TRAIL-R2 binders and TRAIL-R2 at the membrane level.

In the present study, we investigated at the membrane level the cell dependent variability of the apoptosis induced by TRAIL-R2 specific ligands. For this purpose, we used synthetic multivalent peptides with a controlled degree of oligomerization that are specific of the TRAIL-R2 receptor (named TRAILmim/DR5), previously shown to induce TRAIL-R2-dependent apoptosis of BJAB cells when used as dimers or in higher oligomerization states [28]. Here we analyzed the ability for monomeric and dimeric peptides to induce apoptosis in three cancer cell lines, B lymphoma BJAB, T lymphoma Jurkat and colon cancer HCT116. We showed that while BJAB, Jurkat and HCT116 cells expressing TRAIL-R2 were all sensitive to the multivalent rhTRAIL, only BJAB cells underwent apoptosis after divalent TRAILmim/DR5 peptide treatment. To understand this discrepancy, we investigated the TRAIL-R2 binding properties of the peptides. We used surface plasmon resonance (SPR) to characterize their binding to recombinant TRAIL-R2 at a sensor surface, and the LigandTracer ${ }^{\circledR}[29,30]$ to monitor in real time their binding with TRAIL-R2 at the surface of living cells. Moreover we investigated the heterogeneity of kinetic data recorded with LigandTracer by kinetic distribution analysis [31] using the tool Interaction Map ${ }^{\circledR}$ [32-34]. Our data suggest a relationship between the cell surface binding properties of the TRAIL-R2 ligands and their proapoptotic activity, which might be used as predictive tool of their therapeutic potential or that of monoclonal antibodies targeting TRAIL-R2 for clinical trials. 


\section{RESULTS}

\section{Divalent TRAILmim/DR5 induce apoptosis in BJAB cells but not in HCT116 and Jurkat cells}

We previously described two cyclic peptides, named $1 \mathrm{~m}$ and $2 \mathrm{~m}$ in their monovalent forms that only differ by the position of a lysine in their sequence (see Supplementary Materials). Their divalent forms, known as $1 \mathrm{~d}$ and $2 \mathrm{~d}$ respectively, bound to TRAIL-R2 with high affinity as measured by SPR and induced apoptosis of various cell lines $[27,28]$. In the present study, we compared the pro-apoptotic activity of $1 \mathrm{~d}$ and $2 \mathrm{~d}$ on the human Burkitt lymphoma BJAB, T leukemia Jurkat and the colon carcinoma HCT116 cell lines. As shown by flow cytometry using an anti-TRAIL-R2 antibody, these 3 cell lines express TRAIL-R2 (Figure 1A), with a similar amount for BJAB and Jurkat and twice lower than HCT116 (Figure 1B). BJAB and HCT116 express TRAIL-R1 but neither TRAIL-R3 nor -R4 (Figure 1A). As expected, the hexameric form of rhTRAIL named SPK (Figure 1C) induced apoptosis in the three cell lines. By contrast, while BJAB cells underwent apoptosis when treated with $1 \mathrm{~d}$ and $2 \mathrm{~d}$ (Figure 1D, left panel), two divalent TRAILmim/DR5 peptides, Jurkat or HCT116, albeit expressing TRAIL-R2, displayed strong resistance, and limited apoptosis only detected at the highest peptide concentrations (Figure 1D, middle and right panel). Noteworthy, $2 \mathrm{~d}$ was more efficient than $1 \mathrm{~d}$ in inducing BJAB cell death as shown by the $\mathrm{IC}_{50}$ of $0.03 \mu \mathrm{M}$ for $2 \mathrm{~d}$ and $9 \mu \mathrm{M}$ for $1 \mathrm{~d}$.

\section{Divalent TRAILmim/DR5 peptides 1d and 2d bound strongly to the surface of BJAB cells expressing TRAIL-R2, but weakly to HCT116 and Jurkat cells}

To investigate the reasons why BJAB, Jurkat and HCT116 cells dysplay different sensitivity to $1 \mathrm{~d}$ and $2 \mathrm{~d}$ peptide-induced apoptosis, the binding of fluorescent (ATTO 488) $1 \mathrm{~d}$ (f1 d) and $2 \mathrm{~d}$ (f2 d) peptides onto living $\mathrm{BJAB}$ and HCT116 cells was monitored in real time using the LigandTracer technology (all experimental details related to the preparation of labeled peptides as well as analytical data can be found in the Supplementary data). In a first set of experiments, we verified that the presence of the fluorochrome did not affect the proapoptotic activity of the peptides (Figure 2A) or their capacity to interact with sensor immobilized recombinant TRAIL-R2 by SPR (see Table 1). Using flow cytometry, we also demonstrated that $\mathrm{f1d}$ and $\mathrm{f} 2 \mathrm{~d}$ bound on BJAB and HCT116 cells, but not on BJAB or HCT116 cells deficient for TRAIL-R2 (Figure 2B), indicating that the two fluorescent peptides bound on the cell surface in a receptor-dependent manner.
The cell-surface binding kinetics of the dyelabeled peptides f1d and $\mathrm{f} 2 \mathrm{~d}$ were then analyzed with the LigandTracer. BJAB and HCT116 cells expressing or not TRAIL-R2 as well as the TRAIL-R2 ${ }^{+}$Jurkat cells were put in presence of increasing doses $(10,30$ and, for fld, $90 \mathrm{nM}$ ) of each fluorescent peptide, added successively approximately every two hours before removing the peptide to analyze the dissociation phase. Plots of the variation in fluorescence signal over time recorded with the peptides are shown in Figures 3. Despite some variations in fluorescence levels attributed to differences in the number of cells fixed onto the glass slide, fluorescent signals $>25$ were reached for both peptides f1d and f2d on $\mathrm{BJAB}$ cells that expressed TRAIL-R2 (Figure 3A and $3 \mathrm{C}$, green curves). By contrast, the two fluorescent peptides produced weak signals when BJAB cells were deficient for TRAIL-R2 (Figure 3A and 3C, blue curves) showing that their binding was dependent on the presence of TRAIL-R2. The complexes between the peptides and TRAIL-R2 were quite stable, as they dissociated slowly after peptide removal from the solution. In contrast to their behavior with BJAB cells, the fluorescent peptides bound weakly to HCT116 cells expressing TRAIL-R2, and dissociation from these cells occurred nearly as rapidly after removal of the peptide (Figure 3B and 3D, black curve) as on HCT116 cells deficient for TRAIL-R2 (Figure 3B and 3D, purple curve). These observations suggest that the dimeric peptides bind to HCT116 cells that express TRAIL-R2, but with a weak complex stability. A weak binding signal, if any, was observed with the f2d peptide on Jurkat cells (Figure 3E). Weak binding was also observed when the fluorescent monovalent $1 \mathrm{~m}$ peptide was incubated with BJAB cells (Figure 3E). Altogether these results indicate a relationship between the stability of the complexes (peptides/TRAIL-R2) formed at the cell surface and their pro-apoptotic activity: dimers fld and $\mathrm{f} 2 \mathrm{~d}$, that showed strong binding to BJAB cells, induced apoptosis whereas the same peptides bound weakly to Jurkat and HCT116 and scarcely induced their apoptosis. Similarly peptide $\mathrm{f} 1 \mathrm{~m}$ showed weak binding (Figure 3E) and did not induce apoptosis in BJAB cells (Figure 2A).

To go further in the molecular bases of these contrasted binding modes and ability to induce apoptosis, we investigated the oligomerization state of TRAIL-R2 at the cell membrane of the various cell lines in the absence of ligand. For this, HCT116 and BJAB were chemically cross-linked with the non-permeable reagent $\mathrm{BS}^{3}$ [35]. Western blot analysis revealed that a large portion of TRAIL-R2, migrating at $\sim 50 \mathrm{kDa}$, shifted to an oligomer of approximately $200 \mathrm{kDa}$ in cross-linked cell lysates of BJAB (Figure 4). By contrast, the shift to the oligomeric form was nearly not occurring in HCT116 lysates. This discrepancy in TRAIL-R2 oligomerization state could explain the differences in binding mode and apoptosis induction observed with the divalent TRAILmim/DR5. 
Indeed the presence of oligomers at the cell surface could favor dimeric binding, resulting in complex stabilization.

\section{Divalent TRAILmim/DR5 1d and 2d present differences in their mode of binding to} TRIAL-R2, both at sensor and at cell surfaces

Experiments showed in Figure 1D suggested that $2 \mathrm{~d}$ was more efficient than $1 \mathrm{~d}$ to induce $\mathrm{BJAB}$ apoptosis. To examine if this difference in efficiency might result from a difference in the mode of recognition, we analyzed the interaction of the dimeric peptides with sensor-immobilized recombinant TRAIL-R2 using SPR and further evaluated LigandTracer data recorded with TRAIL-R2 expressing BJAB cells (Figure 3A and 3C).

For this, the SPR binding profiles of the divalent $(1 \mathrm{~d}$ and $2 \mathrm{~d}$ ) and monovalent $(1 \mathrm{~m}$ and $2 \mathrm{~m}$ ) peptides injected on recombinant TRAIL-R2 immobilized on a sensor surface were compared (Figure 5). Kinetic parameters were calculated by global fitting of the kinetic curves using a Langmuir binding model. As shown in Table 1, the equilibrium constants $\left(\mathrm{K}_{\mathrm{D}}\right)$ calculated with the divalent peptides were always smaller than those of the monovalent peptides. Furthermore, the $\mathrm{K}_{\mathrm{D}}$ obtained with peptide $2 \mathrm{~d}$ was approximately 400 fold smaller than the $\mathrm{K}_{\mathrm{D}}$ obtained with peptide $1 \mathrm{~d}$. This gain in affinity was due to a faster association $\left(2 \mathrm{~d}: \mathrm{k}_{\text {on }}=1.5 \times 10^{6} \mathrm{M}^{-1} \mathrm{~s}^{-1}, 1 \mathrm{~d}: \mathrm{k}_{\text {on }}=2.8 \times\right.$
A
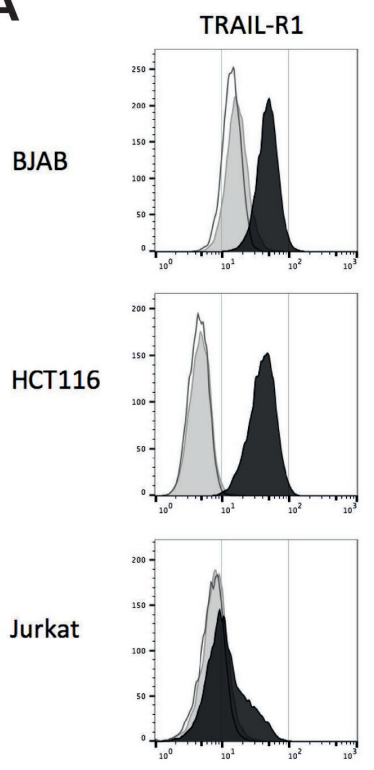
$\square$ vehicle
TRAIL-R2
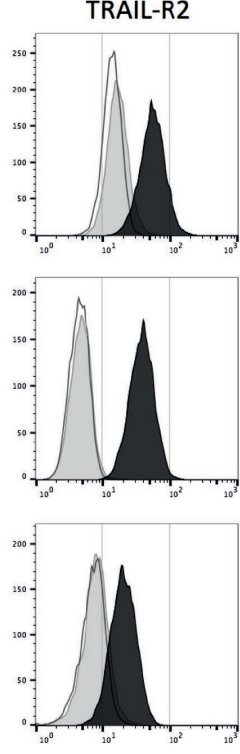

isotype control mAb
TRAIL-R3
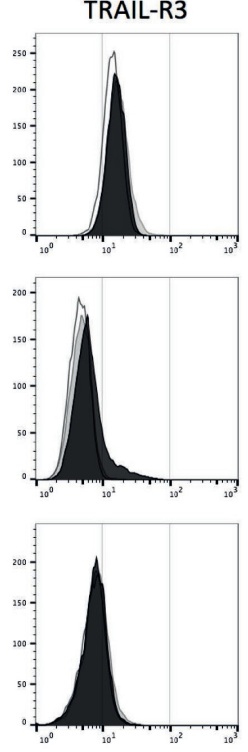

mAb anti-TRAIL-R
B
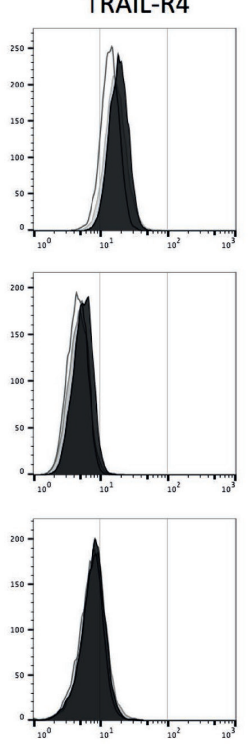

C
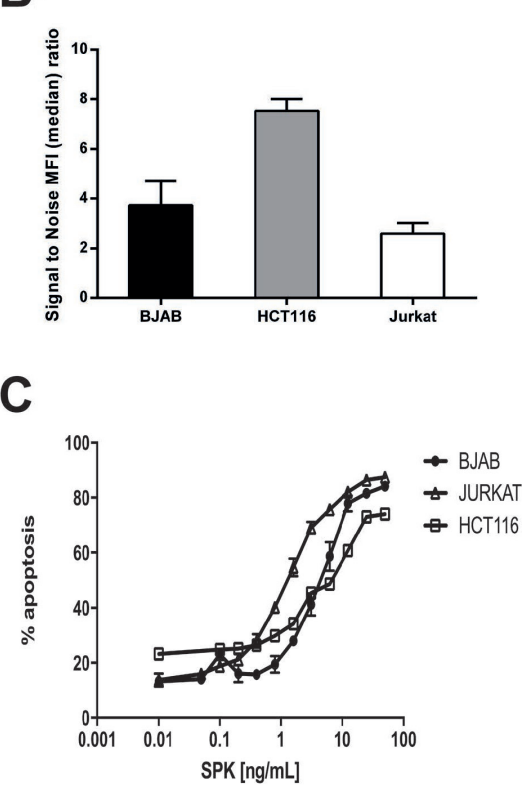

D

BJAB

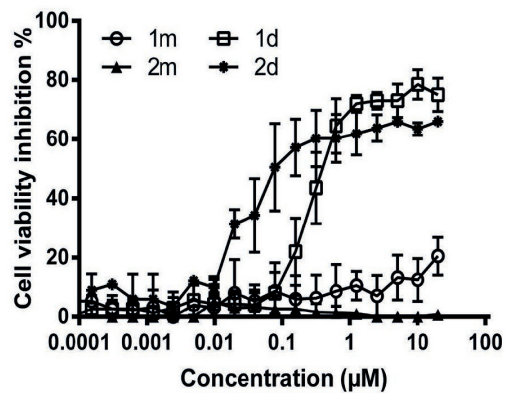

HCT116

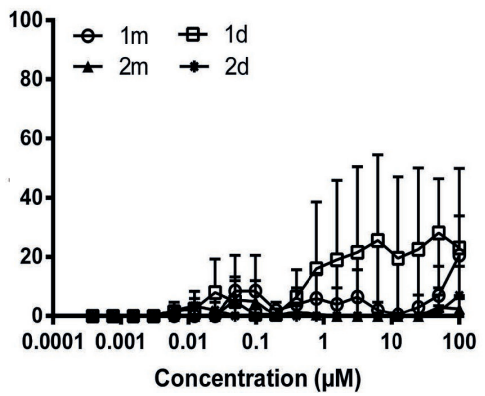

Jurkat

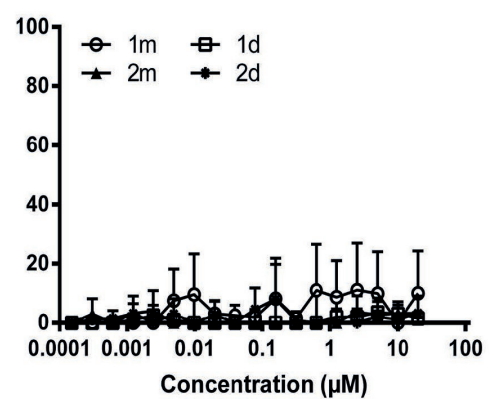

Figure 1: Divalent TRAILmim/DR5 induce apoptosis in BJAB cells but not in HCT116 and Jurkat cells. (A, B) BJAB, HCT116 and Jurkat cells were stained with a monoclonal antibody targeting TRAIL-R1, R2, R3 or R4. The TRAIL receptor expression was monitored by flow cytometry. The resulting fluorescence histograms are showed in (A) and the signal to noise ratio of the median of fluorescence intensity between control isotype and TRAIL-R2 specific labeling, that are correlated with the level TRAIL-R2 expression, in (B). (C, D) Inhibition of cell viability, as deduced from metabolic activity measured by MTS assay for BJAB, HCT116 or Jurkat cells treated with different concentrations of SPK (C) or monovalent (1 m, $2 \mathrm{~m}$ ) or divalent (1 d, $2 \mathrm{~d})$ peptides (D). Results are expressed as \% of cell viability inhibition according to the following formula: cell viability inhibition $\%=\left(\right.$ OD treatment/OD $(100 \%$ viability $\left.){ }^{*} 100\right)$, were cells incubated with medium alone were considered as $100 \%$ of viability. Values correspond to the mean of 3 independent experiments \pm SEM. 
$\left.10^{4} \mathrm{M}^{-1} \mathrm{~s}^{-1}\right)$ and a slower dissociation $\left(2 \mathrm{~d}: \mathrm{k}_{\text {off }}=1.8 \times 10^{-4}\right.$ $\left.\mathrm{s}^{-1}, 1 \mathrm{~d} \mathrm{k}_{\text {off }}=1.4 \times 10^{-3} \mathrm{~s}^{-1}\right)$. The dissociation rate constants recorded with the labeled peptides $\mathrm{flm}$, fld and $\mathrm{f} 2 \mathrm{~d}$ were very similar to those recorded with the unlabeled peptides $1 \mathrm{~m}, 1 \mathrm{~d}$ and $2 \mathrm{~d}$, respectively (Table 1 ).

The stoichiometry of the interactions between divalent peptides and TRAIL-R2 was estimated from comparing the fitted $\mathrm{R}_{\max }$ values (amount of peptide bound at surface saturation) of the divalent peptides $1 \mathrm{~d}$ and $2 \mathrm{~d}$ with that of the monovalent peptide $1 \mathrm{~m}$. If one divalent peptide molecule binds to one TRAIL-R2 molecule (monovalent binding), $\mathrm{R}_{\max }$ calculated for the divalent peptide would be twice that of the monovalent peptide, because its molecular weight is twice that of the monovalent peptide. By contrast, if one divalent peptide molecule binds to two TRAIL-R2 molecules (bivalent binding), $\mathrm{R}_{\max }$ would be the same for the monovalent and the divalent peptides. The $\mathrm{R}_{\max }$ for $2 \mathrm{~m}$ could not be fitted with confidence because the sample concentrations used were too low to approach surface saturation. As shown in Table 2, the $\mathrm{R}_{\max }$ values for $1 \mathrm{~d}$ and $2 \mathrm{~d}$ were similar to that of $1 \mathrm{~m}$, suggesting that the divalent peptides prevalently bound in a "bivalent" way. As seen in Figure 5, the fits obtained with peptides $1 \mathrm{~d}$ and $2 \mathrm{~d}$ were not perfect. To further investigate the binding modes, we fitted the kinetic curves using complex interaction models instead of the Langmuir model. Although the use of more complex models implies an increase in the number of parameters to be fitted, and therefore a decrease in the resulting chi2 values (statistical parameter of the goodness of fit), the $\mathrm{Chi}^{2}$ values shown in Table 2 indicate that the bivalent analyte and the heterogeneous ligand models are significantly more appropriate to fit $2 \mathrm{~d}$ data $(\sim 10$ fold smaller $\mathrm{Chi}^{2}$ compared to that obtained with the $1: 1$ model). On the contrary, the same complex models were not more appropriate than the Langmuir model to fit $1 \mathrm{~d}$ data (similar $\mathrm{Chi}^{2}$ whatever the model is).
A

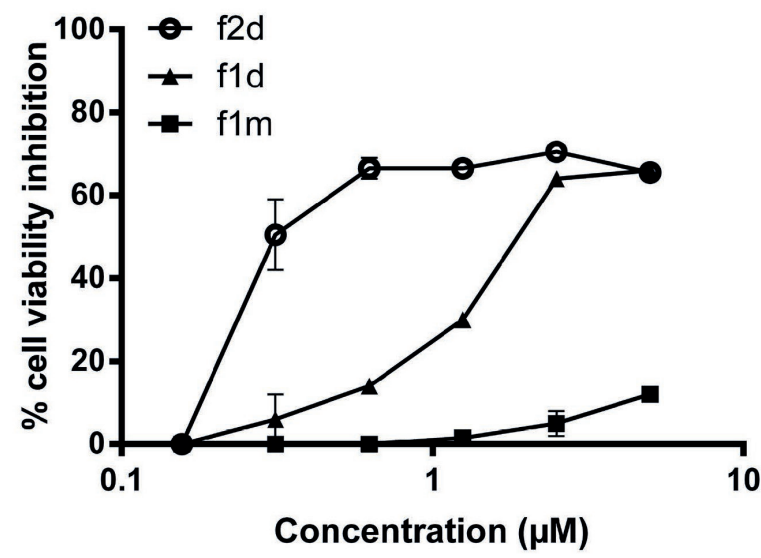

B

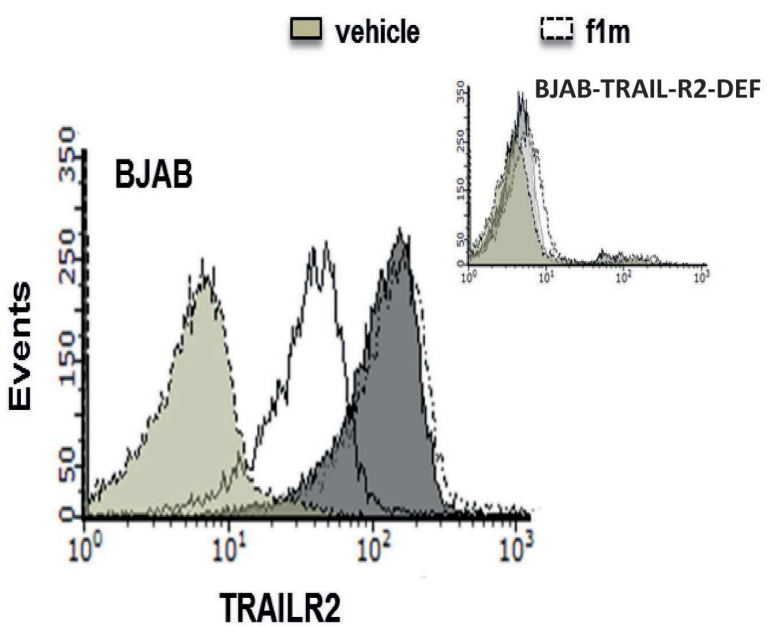

HCT116

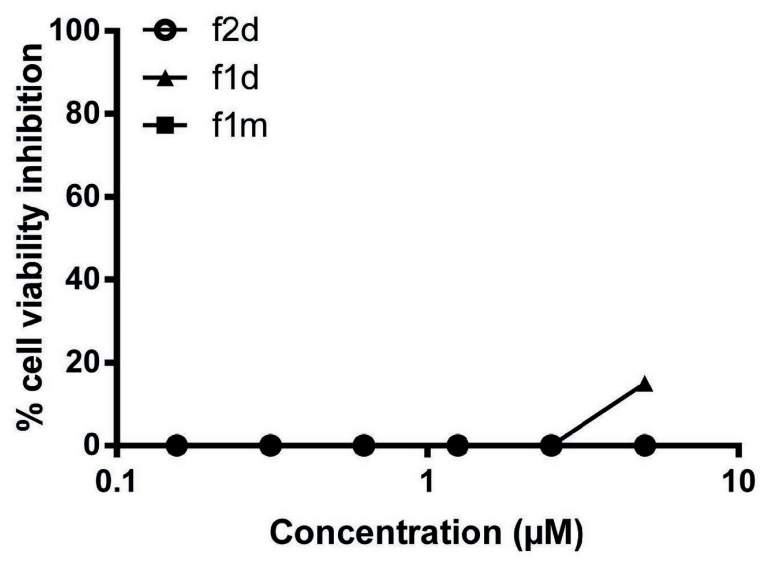

f1d

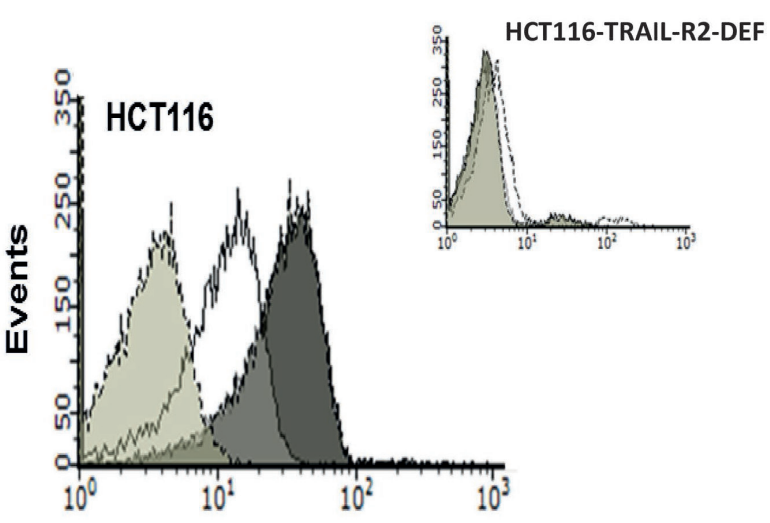

TRAILR2

Figure 2: Fluorescent dye Atto488 does not affect peptide mono- or divalent binding activity on BJAB and HCT116. (A) MTS assay was assessed for BJAB and HCT116 cells treated with different concentrations of monovalent (f1 m) or divalent (f1 d, f2 d) peptides. (B) BJAB and HCT116 cells expressing or not TRAIL-R2 were stained with labeled peptides f1 d and $\mathrm{f} 2 \mathrm{~d}$ and binding was monitored in flow cytometry. 
Table 1: Binding parameters for the interaction between the peptides and sensor-immobilized TRAIL-R2

\begin{tabular}{llcc}
\hline Peptides & $\mathbf{k}_{\text {on }}\left(\mathbf{M}^{-1} \times \mathbf{s}^{-1}\right)$ & $\mathbf{k}_{\text {off }}\left(\mathbf{s}^{-1}\right)$ & $\mathbf{K}_{\mathbf{D}}(\mathbf{M})$ \\
\hline $\mathbf{1 m}$ & $(5.3 \pm 1.5) \times 10^{3}$ & $(2.6 \pm 0.5) \times 10^{-3}$ & $(5.1 \pm 0.5) \times 10^{-7}$ \\
$\mathbf{1 d}$ & $(2.8 \pm 0.2) \times 10^{4}$ & $(1.4 \pm 0.2) \times 10^{-3}$ & $(5.1 \pm 0.8) \times 10^{-8}$ \\
$\mathbf{2 m}$ & $(3.6 \pm 2.8) \times 10^{3}$ & $(1.6 \pm 1.5) \times 10^{-2}$ & $(3.6 \pm 1.4) \times 10^{-6}$ \\
$\mathbf{2 d}$ & $(1.5 \pm 0.3) \times 10^{6}$ & $(1.8 \pm 0.1) \times 10^{-4}$ & $(1.3 \pm 0.3) \times 10^{-10}$ \\
$\mathbf{f 1 m}$ & $(1.4 \pm 0.6) \times 10^{4}$ & $(1.4 \pm 2.9) \times 10^{-3}$ & $(9.8 \pm 1.8) \times 10^{-6}$ \\
$\mathbf{f 1 d}$ & $(2.2 \pm 3.5) \times 10^{4}$ & $(1.4 \pm 0.2) \times 10^{-3}$ & $(6.6 \pm 2.7) \times 10^{-8}$ \\
$\mathbf{f} \mathbf{d}$ & $(1.5 \pm 5.3) \times 10^{5}$ & $(2.6 \pm 0.7) \times 10^{-4}$ & $(1.7 \pm 0.7) \times 10^{-9}$ \\
\hline
\end{tabular}

To go further in this analysis, the binding of fld and $\mathrm{f} 2 \mathrm{~d}$ on $\mathrm{BJAB}$ cells, recorded with the LigandTracer (green curves in Figure 3A and 3C), were deciphered using a mathematical method (kinetic distribution analysis) that permits to investigate the heterogeneity of kinetic data. A visual inspection of the binding traces suggested differences in binding modes. Indeed a $90 \mathrm{nM}$ concentration of fld (Figure 3A) was required to reach sufficient curvature to perform kinetic fitting, while a $30 \mathrm{nM}$ concentration of $\mathrm{f} 2 \mathrm{~d}$ was sufficient (Figure 3C). The fitted binding curves and corresponding Interaction Maps are shown in Figure 6. All maps show several peaks that differ predominantly by their position on the $\mathrm{x}$-axis (stability), with a dominant high-affinity interaction (left peak). The residual binding signal was interpreted as a single low-affinity interaction (right peak) in $2 \mathrm{~d}$ maps (Figure 6B) and as several ill-defined peaks in 1d maps (Figure 6A). Furthermore, the high-affinity peak tended to be positioned slightly higher on the y-axis (recognition) in $2 \mathrm{~d}$ compared $1 \mathrm{~d}$ maps, indicating a slightly faster association of $2 \mathrm{~d}$ to the cell surfaces.

Overall, LigandTracer experiments and kinetic distribution analysis of the resulting data, which highlight subtle differences in the interaction of $1 \mathrm{~d}$ and $2 \mathrm{~d}$ with TRAIL-R2 expressed on BJAB living cells, are consistent with the kinetic differences in the TRAIL-R2 binding modes of $1 \mathrm{~d}$ and $2 \mathrm{~d}$ calculated from SPR data.

\section{DISCUSSION}

Despite the detailed knowledge of signaling events downstream TRAIL-R activation, the initiating events in TRAIL-induced apoptosis, especially at the membrane level, are not clearly understood [7] probably because of the lack of tools that enable the monitoring of cellular binding $[36,37]$. Indeed, biophysical methods such as SPR monitor the interaction of ligands with recombinant receptors immobilized on a surface, a set-up that only partially mimics receptor presentation at a cell surface. SPR binding data may not fully transpose to in cellulo conditions where, for example, receptor clustering is typically required for signaling. It is known that the TRAIL-R2 receptor is preoligomerized via its PLAD domain (Pre-Ligand Associated
Domain) at the membrane surface in absence of TRAIL [10]. TRAIL binding on pre-oligomerized TRAIL-R2 leads to receptor clustering in a highly organized network that is required to induce efficient apoptosis [11]. At least five mAbs targeting TRAIL-R2 were developed and evaluated in clinical trials [15]. Unfortunately, most of them are weak agonists, most likely because they are unable to induce the receptor network configuration required for apoptosis. In these conditions, characterization of the binding of ligands targeting TRAIL-Rs is crucial to understand which properties are required to initiate apoptosis signaling and optimize TRAIL receptor-targeted strategies, and in particular for divalent agonists.

We previously described synthetic peptides (1 and 2) targeting the TRAIL-R2 receptor and that induce TRAILR2-dependent apoptosis of BJAB cells, in divalent and trivalent forms [27]. SPR experiments indicated that both $1 \mathrm{~d}$ and $2 \mathrm{~d}$ formed stable complexes with recombinant TRAIL-R2 covalently immobilized on a sensor surface. We show here that, while HCT116 and Jurkat cells were sensitive to hexameric rhTRAIL (SPK) induced apoptosis, the dimeric peptides largely failed to kill them. Results from flow cytometry experiment showed that the two cell lines express different amount of TRAIL-R2 receptors: HCT116 express much more receptors than BJAB or Jurkat but the two divalent peptides bound to TRAIL-R2 expressed on HCT116 and BJAB cell lines. Nevertheless, flow cytometry does not provide information on peptide binding properties, which might differ in the three cell lines and explain differences in apoptosis-induction efficiency. To investigate this point, we used the LigandTracer to monitor in real time the binding between the peptides and TRAIL-R2 receptors expressed on BJAB, Jurkat and HCT116 living cells. The LigandTracer technology, associated with the kinetic distribution analysis of the resulting binding traces, enabled a detailed comparison of the binding mode of the peptides to receptors on the two cell lines.

We succeeded in recording kinetic curves for the binding of the two dimeric and of one monomeric peptide (Figure 3) to three cell lines. In order to preserve physiological conditions, we used BJAB, HCT116 and Jurkat that express a natural level of TRAIL-R2 receptors and we demonstrated that binding was receptor-specific by 
monitoring peptide binding on cells that did not express TRAIL-R2. The binding signal observed in cells expressing TRAIL-R2 was systematically higher than that observed in cells deficient for TRAIL-R2, even though the increase was small in the case of HCT116 cells (Figure 3B and 3D). The faint signal observed in TRAIL-R2-deficient cells might result from unspecific binding due for example to the presence of the fluorescent dye.

The LigandTracer kinetic data reveal drastic differences in the binding modes to TRAIL-R2 depending on both the nature of the peptide and the cell type. The monomeric peptide dissociated more quickly from BJAB cells than the dimeric peptides. This behavior was also observed in SPR experiments using the recombinant receptor (Figure 5) and can be attributed to the avidity of the dimeric peptides for adjacent receptors on cell or sensor surfaces. Interestingly subtle differences were also observed between dimeric peptides in binding TRAIL-R2: the faster association of $2 \mathrm{~d}$ compared to $1 \mathrm{~d}$ was apparent in the maps calculated from LigandTracer data (Figure 6), although less striking than in SPR. The presence of two well-resolved peaks in the $2 \mathrm{~d}$ maps may support the finding that SPR data were well fitted only with the bivalent or heterogeneous binding models.

In contrast to the peptide-dependence of binding, the cell-line dependence was not predictable from SPR data. The dimeric peptides, which both showed strong binding in SPR experiments, dissociated slowly from BJAB cells (Figure 3A and 3C), and immediately from HCT116 cells (Figure 3B and 3D). The cell-line dependence of binding has been repeatedly reported in cell-binding studies using the LigandTracer (for example [32, 33, 38-40]) but rarely related to biologic activity. We demonstrate here that the binding mode of the peptides to cell surfaces is correlated with their efficiency in inducing apoptosis as the divalent peptides formed stable complexes at BJAB cell surfaces and induced their apoptosis efficiently whereas the weak cell surface binding of the monovalent peptides on the
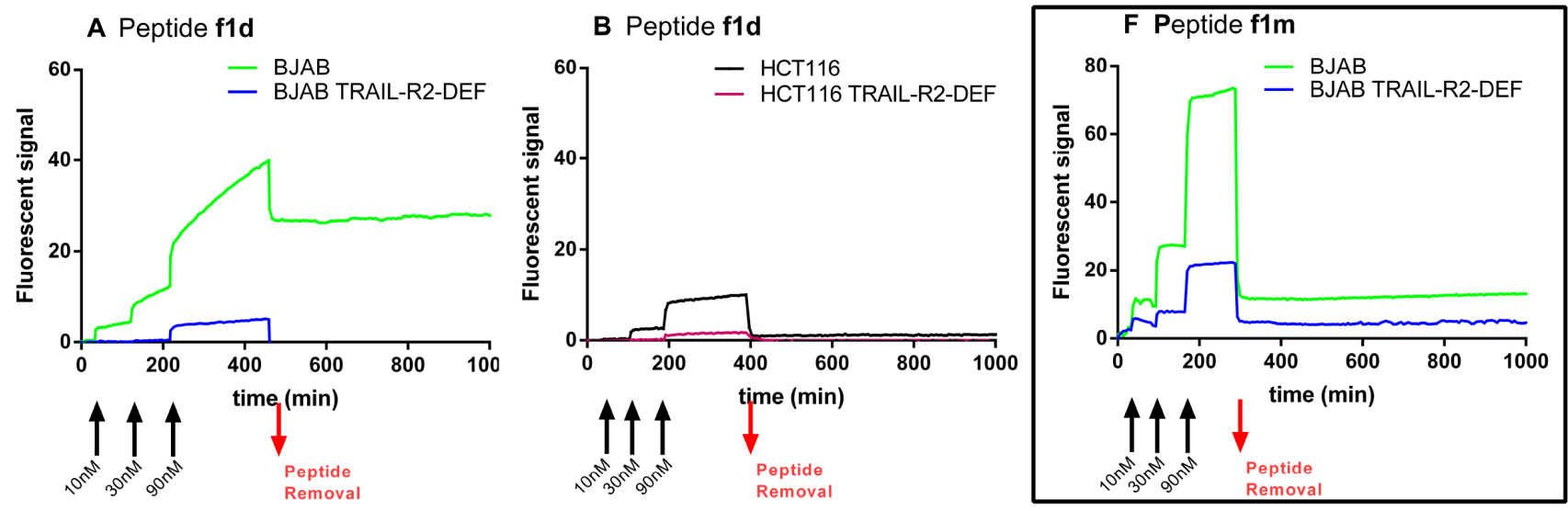

\section{Peptide f2d}

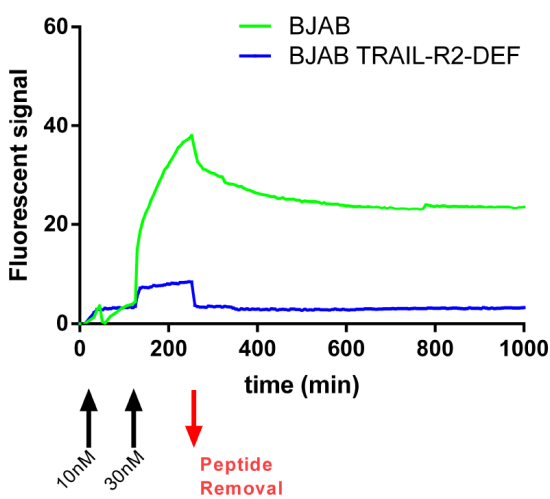

D Peptide f2d

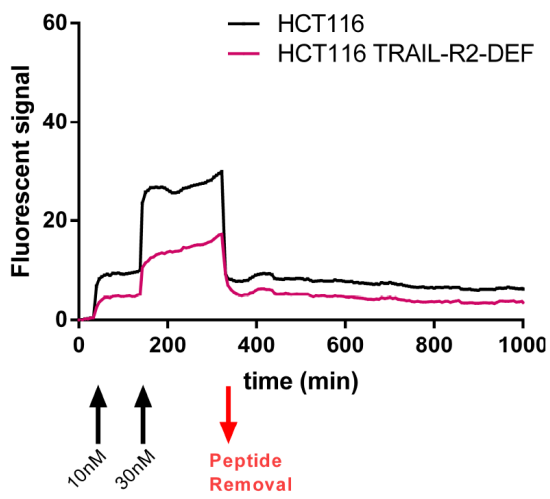

E Peptide f2d

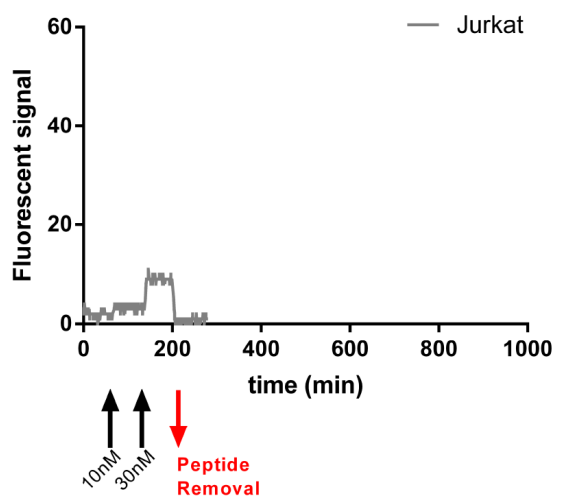

Figure 3: Divalent peptides f1d and f2d but not the monovalent f1 $\mathrm{m}$, form stable complexes with TRAIL-R2 expressed on BJAB cells whereas the same peptides bound weakly to HCT116 and Jurkat cells. (A-E). Representative kinetic curves recorded with the LigandTracer for the interaction of divalent peptides f1d (A, B) and f2d (C, D, E) with (A, C): BJAB (green curves) and BJAB-TRAIL-R2-DEF (blue curves) cells or (B, D): HCT116 (black curves) and HCT116-TRAIL-R2-DEF (purple curves), or (E): Jurkat cells. (F) Binding curves recorded for the interaction between monovalent peptide f1m on BJAB expressing TRAIL-R2 (green curve) or not (blue curve). The black arrows indicate the addition of peptides at increasing concentrations ( $10 \mathrm{nM}, 30 \mathrm{nM}, 90 \mathrm{nM})$ as indicated. The red arrows indicate peptide removal. 


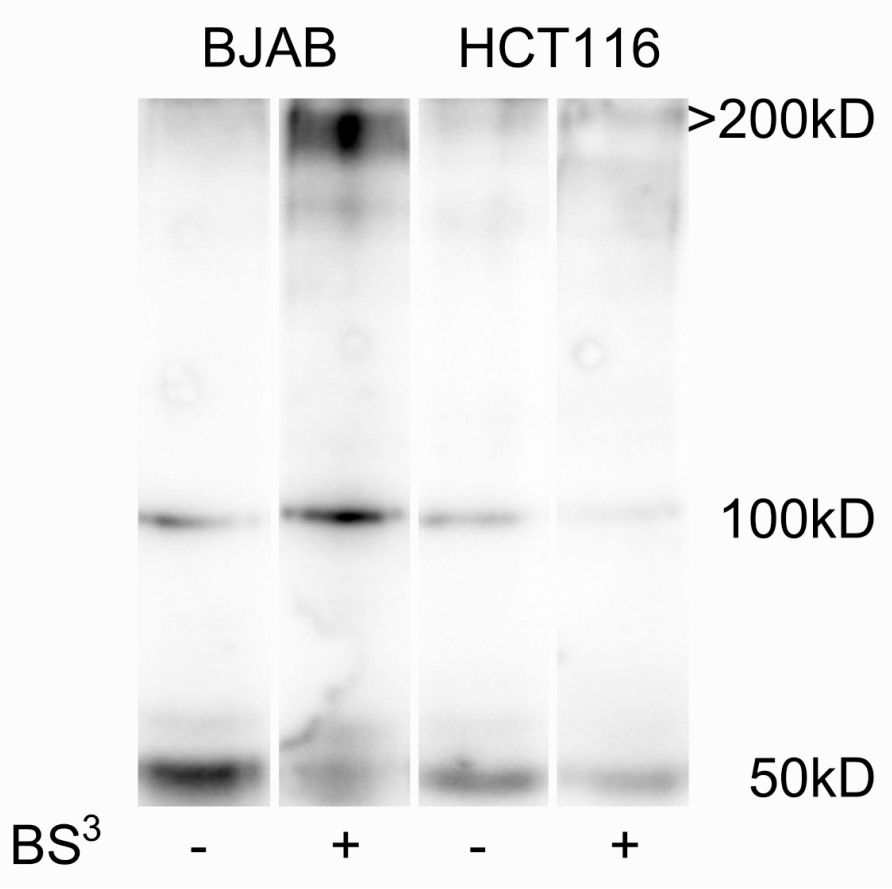

Figure 4: TRAIL-R2 is highly oligomerized before ligand addition in BJAB but not in HCT116 cells. The two cell lines were incubated or not with $5 \mathrm{mM} \mathrm{BS}^{3}$ for $30 \mathrm{~min}$. After, $\mathrm{BS}^{3}$ quenching and cell lysis, TRAIL-R2, monomer $(50 \mathrm{kD})$ or crosslinked versions $(>200 \mathrm{kDa})$, were revealed on western blot using a specific monoclonal anti-TRAIL-R2 antibody.
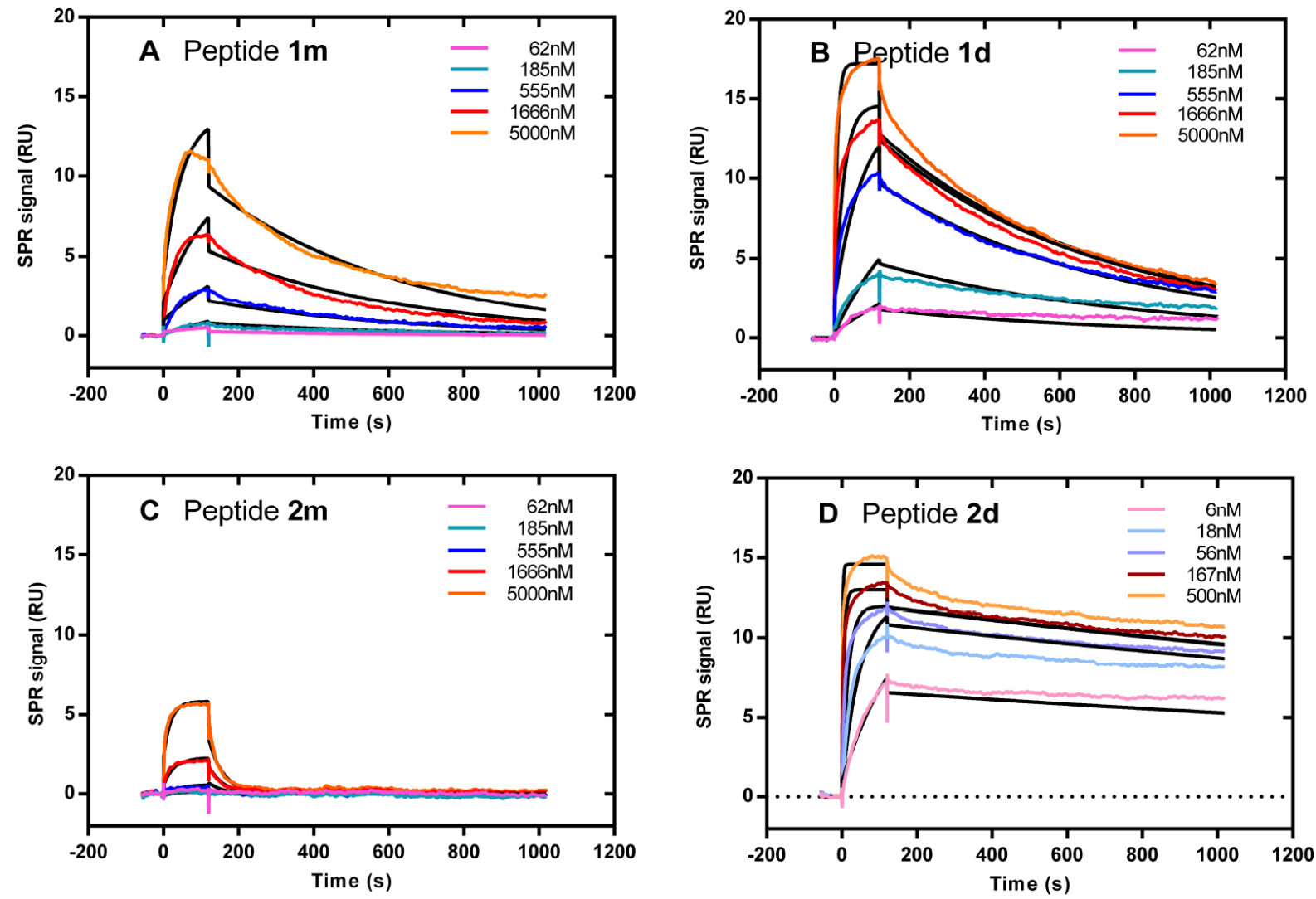

Figure 5: Divalent peptides $1 \mathrm{~d}$ and $2 \mathrm{~d}$ bind with stronger affinity than monovalent peptides $1 \mathrm{~m}$ and $\mathbf{2 m}$ to sensorimmobilized TRAIL-R2. Representative kinetic SPR curves recorded with monovalent $1 \mathrm{~m}(\mathbf{A})$ and $2 \mathrm{~m}(\mathbf{C})$ and divalent $1 \mathrm{~d}(\mathbf{B})$ and $2 \mathrm{~d}$ (D) peptides. The fitted curves using the Langmuir one:one model are shown in black. 
Table 2: Goodness of fit $\left(\mathrm{Chi}^{2}\right)$ of two SPR data sets to simple and complex interaction models

\begin{tabular}{|c|c|c|c|c|c|c|c|c|c|}
\hline \multirow[b]{3}{*}{ Peptide } & \multirow[b]{3}{*}{ Surface $^{\mathrm{a}}$} & \multirow[b]{3}{*}{$\mathbf{R}_{\max }$} & \multicolumn{7}{|c|}{ Model used for data fitting } \\
\hline & & & \multirow{2}{*}{$\frac{\text { Langmuir }}{\mathrm{Chi}^{2}}$} & \multicolumn{2}{|c|}{$\begin{array}{c}\text { Bivalent } \\
\text { analyte }\end{array}$} & \multicolumn{2}{|c|}{$\begin{array}{c}\text { Heterogenous } \\
\text { ligand }\end{array}$} & \multicolumn{2}{|c|}{ Two state reaction } \\
\hline & & & & $\mathrm{Chi}^{2}$ & Ratio $^{b}$ & $\mathrm{Chi}^{2}$ & Ratio & $\mathrm{Chi}^{2}$ & Ratio \\
\hline \multirow{2}{*}{$1 \mathrm{~m}$} & 1 & 33 & 0.92 & 0.88 & 1.0 & 0.59 & 1.6 & 0.76 & 1.2 \\
\hline & 2 & 11 & 0.10 & 0.09 & 1.1 & 0.04 & 2.7 & 0.07 & 1.4 \\
\hline \multirow{2}{*}{$1 \mathrm{~d}$} & 1 & 38 & 2.13 & 1.22 & 1.7 & 1.21 & 1.8 & 1.22 & 1.7 \\
\hline & 2 & 13 & 0.25 & 0.15 & 1.7 & 0.15 & 1.6 & 0.15 & 1.7 \\
\hline \multirow{2}{*}{$2 \mathrm{~d}$} & 1 & 33 & 4.54 & 0.49 & 9.3 & 0.32 & 14.4 & 2.04 & 2.2 \\
\hline & 2 & 12 & 0.62 & 0.06 & 10.5 & 0.06 & 10.5 & 0.26 & 2.4 \\
\hline
\end{tabular}

aData obtained on two TRAIL-R2 surfaces with different $\mathrm{R}_{\max }$ values, as fitted using the one:one interaction model, are presented.

${ }^{b}$ Ratio of the $\mathrm{Chi}^{2}$ obtained with the Langmuir model to the $\mathrm{Chi}^{2}$ obtained with the complex interaction models.

two cell lines and of the bivalent peptides on HCT116 correlate with low induction of apoptosis. Besides the major differences in binding and apoptosis-induction between cell lines, we also observed subtle differences within the same cell line. Indeed the dimeric peptides $1 \mathrm{~d}$ and $2 \mathrm{~d}$ were not equivalent in their ability to induce
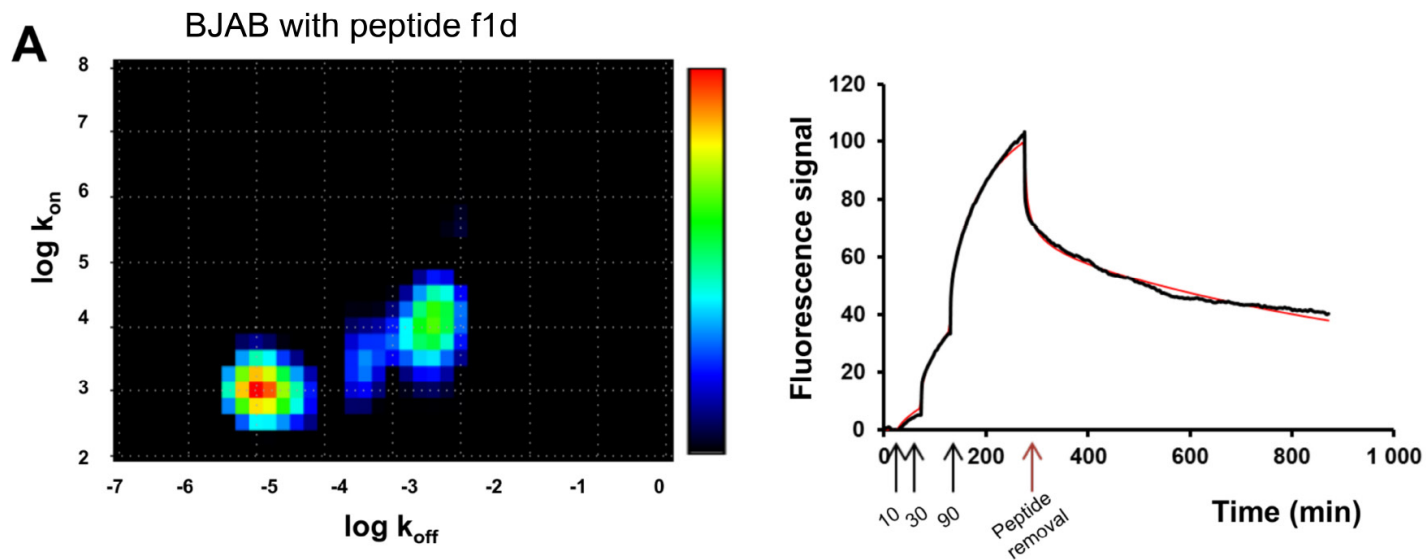

B
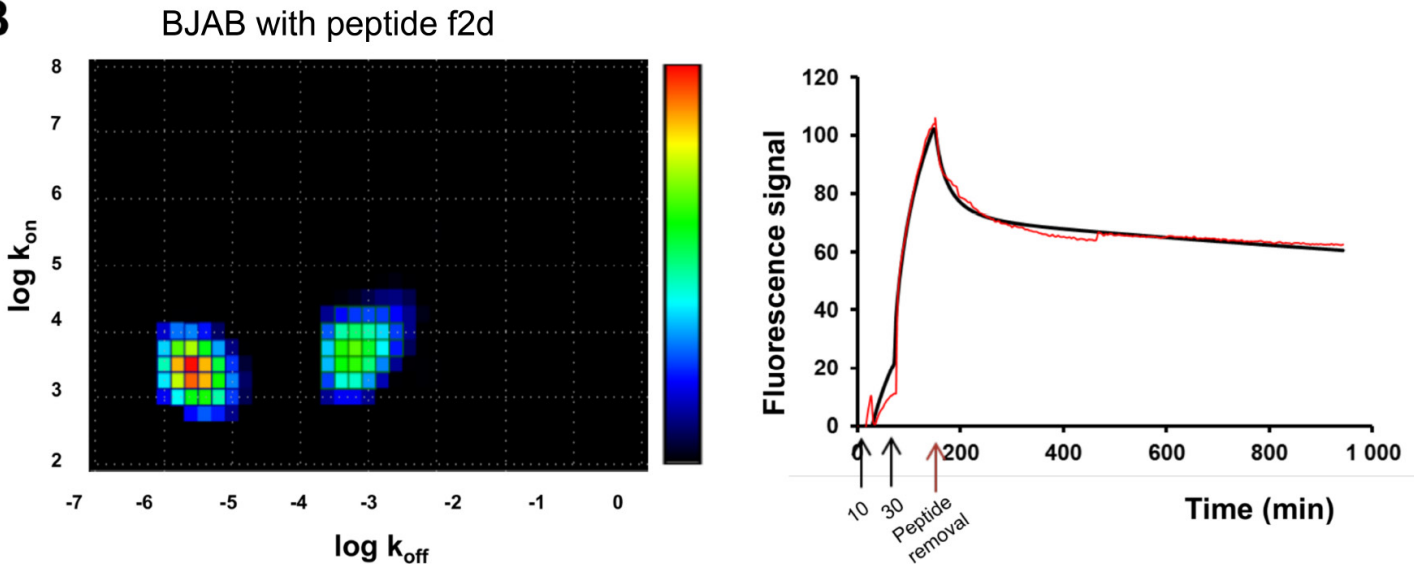

Figure 6: Divalent peptides f1d and f2d present differences in BJAB binding modes. Representative interaction maps (left) calculated from real time LigandTracer binding curves (right, red: experimental binding curve, black: fitted curve) for the interaction between divalent peptides f1d (A) or f2d (B) on BJAB expressing TRAIL-R2. Colors represent the relative degree of contribution to the binding signal (red: large contribution, blue: small contribution). The black arrows on the curves (right) correspond to the addition of 10 , 30 and $90 \mathrm{nM}$ of peptide f1d (A) or 10 and $30 \mathrm{nM}$ of peptide $\mathrm{f} 2 \mathrm{~d}(\mathrm{~B})$ to the cells. The red arrows indicate the removal of peptides. 
apoptosis in BJAB cells (Figure 1D). The correlation between binding and apoptosis-induction may therefore hold true not only for overall affinity, but also for more subtle binding characteristics such as dissociation. In line with these findings, it is worthy to note that dissociation of rhTRAIL to TRAIL-R2 has been measured by SPR to be also pretty poor (O. Micheau, personal communication).

The molecular bases for these observed differences in binding mode and ability to induce apoptosis is still largely unknown. The divalent synthetic peptides are likely to discriminate differently between TRAIL-R2 derived structures or other TRAIL receptors, compared to rhTRAIL which induced apoptosis in BJAB, Jurkat and HCT116 cell lines. Features such as receptor nature, i.e. expression level, organization, location or glycosylation could explain why a dimeric peptide displays a lower binding and apoptosis efficiency, compared to the hexameric rhTRAIL in HCT116 cells. For example TRAIL-R2 might present a different pattern of O-glycosylation sites in BJAB, Jurkat and HCT116 cells thus facilitating or limiting the recruitment of receptors to induce apoptosis [41]. Another explanation could be the oligomerization state of TRAIL-R2 at the cell membrane. TRAIL-R2 on the cells can form homodimer leading to receptors clustering to a higher extend thus facilitating dimeric peptide binding and inducing a stronger apoptosis signal. We performed some experiments suggesting that this hypothesis should be privileged. Indeed, using cross-linking (Figure 4), we showed that TRAIL-R2 was expressed in a high oligomerization state in BJAB cells that displays a higher binding and apoptosis sensitivity in comparison with HCT116. TRAIL-R2 on the cells can form homodimer leading to receptors clustering to a higher extend thus facilitating dimeric peptide binding and inducing a stronger apoptosis signal. TRAIL-R2 can also form heteromers with the inhibitor receptor TRAIL-R4 as described in publications $[23,24]$ thus limiting the TRAIL-R2 free receptors available to initiate apoptosis. By contrast, this hypothesis seems more unlikely as we demonstrated that TRAIL-R4 is not expressed on the cell surface of the three cell line used in this study (Figure 1A). We also could exclude an effect of TRAIL-R2 internalization as we previously showed (27) that $2 \mathrm{~d}$ peptide induce a significant amount of internalization in the three cell lines.

In conclusion, we demonstrate that, while divalent peptides $1 \mathrm{~d}$ and $2 \mathrm{~d}$ bound TRAIL-R2 with strong affinity in SPR experiments, their binding mode at the cell surface, as well as their efficiency in cell apoptosis-induction, was cell-line dependent. Based on the observed correlation between peptide binding/dissociation at cell surfaces and pro-apoptotic activity, we propose that the detailed characterization of ligand-cell binding kinetics could be developed as a predictive tool to gain information about the therapeutic efficiency of new divalent ligands but also to rationalize the outcome of cellular assays. For example, it would be tempting to use the LigandTracer to determine the kinetic profiles on cells of a series of known mAbs selected for their high affinity for TRAIL-R2 and agonistic potential, and to correlate the results with their cellular activity profiles.

\section{MATERIALS AND METHODS}

\section{Peptide synthesis}

TRAILmin/DR5 peptides $1 \mathrm{~m}, 2 \mathrm{~m}, 1 \mathrm{~d}$ and $2 \mathrm{~d}$ were synthesized in our laboratory according to previous reports $[27,42]$. The synthesis of the corresponding fluorescent versions namely $1 \mathrm{~m}$-Alexa 488 conjugate ( $\mathrm{flm}$ ), 1d-ATTO 488 conjugate (f1d) and $2 \mathrm{~d}$-ATTO 488 conjugate (f2d) is describe in detail in supporting information. The formulae of all ligands are provided in the Supplementary data. Peptides $1 \mathrm{~m}, 2 \mathrm{~m}, 1 \mathrm{~d}$ and $2 \mathrm{~d}$ were solubilized in $\mathrm{H}_{2} \mathrm{O}$ and prepared in a stock solution at $5 \mathrm{mM}$. Fluorescent conjugate peptides were solubilized in DMSO in a stock solution at $100 \mu \mathrm{M}$.

\section{Cell lines}

The human $\mathrm{T}$ leukemia Jurkat cells provided by ATCC (ATCC number TIB-152) were described to lack TRAIL-R1, R3 and R4 (Figure 1A).

The human Burkitt lymphoma BJAB cells deficient for TRAIL-R2 (BJAB-TRAIL-R2-DEF) as well as BJAB cells in which the expression of TRAIL-R2 was recovered by stable expression of TRAIL-R2 were obtained as described [43] and kindly provided by Andrew Thorburn (Department of Pharmacology, University of Colorado Denver School of Medicine, USA). HCT116 human colon cancer cell lines (HCT116 and HCT116-TRAIL-R2$\mathrm{DEF}$ ) that differ in the presence or absence of TRAIL-R2 expression at cell membrane were obtained after transfection using a pair TRAIL-R2 TALEN plasmids targeting exon 3 [44]. Both cell lines and isogenic derivatives were cultured in RPMI 1640 supplemented with 10\% FBS (Fetal Bovine Serum), $100 \mathrm{U} / \mathrm{mL}$ penicillin and $0.1 \mathrm{mg} / \mathrm{mL}$ streptomycin. Puromycin antibiotic $(0.5 \mu \mathrm{g} / \mathrm{mL})$ was added to the BJAB medium to ensure the maintaining of TRAIL-R2 expression. Cells were maintained at $37^{\circ} \mathrm{C}$ with $5 \% \mathrm{CO}$.

\section{Cell viability assay}

BJAB, Jurkat and HCT116 cells (10 cells/well) were cultured in $100 \mu \mathrm{L}$ of culture medium in 96-flat bottom well plates. The next day, cells were treated with the indicated concentrations of the different TRAILmin/ DR5 peptides. After 24 hours of treatment cell viability measurement was performed by the MTS assay according to the manufacturer specification (Promega Corporation, Madison, WI, USA). 


\section{Crosslinking and western blot analysis}

TRAIL-R2 oligomerization state was evaluated by a chemical cross linking followed by a classical western blot assay as previously described by our group [32]. Briefly, Bis(sulfosuccinimidyl) suberate $\left(\mathrm{BS}^{3}\right)$ is an homobifonctionnal, amine reactive, non cleavable cross-linker with an $11.4 \AA$ spacer arm, synthetized in our laboratory. BJAB and HCT116 cells were washed once in PBS, crosslinked with $5 \mathrm{mM} \mathrm{BS}^{3}$ for 30 min at room temperature then quenched with $20 \mathrm{mM}$ glycine $15 \mathrm{~min}$. Cells were pelleted by centrifugation and lysed in RIPA buffer $1 \mathrm{~h}$ on ice. Total protein concentrations were determined by BiCinchoninic Acid protein assay and $20 \mu \mathrm{g}$ were loaded on an $8 \%$ SDS polyacrylamide gel. Proteins were transferred on a PVDF membrane and probed using an anti-TRAIL-R2 (Millipore).

\section{Staining for flow cytometry analysis}

$10^{6}$ cells were washed in PBS containing $2 \%$ FCS and then incubated at $4^{\circ} \mathrm{C}$ for $30 \mathrm{~min}$ with an anti-TRAIL-R2 antibody (clone BK9 Diaclone, Besançon, France) according to concentration recommended by the manufacturer or with fluorescent peptides at the concentration of $1 \mu \mathrm{M}$. After two washes in PBS-2\% FBS, TRAIL-R2 expression was monitored by flow cytometry (Guava easyCyte ${ }^{\mathrm{TM}}$, Merck Milipore, Darmstadt, Germany) and data were analyzed with InCyte Software (Merck Milipore).

\section{Surface plasmon resonance}

SPR assays were performed on a Biacore $\mathrm{T} 200^{\mathrm{TM}}$, at $25^{\circ} \mathrm{C}$. The running buffer was HBS-EP $[10 \mathrm{mM}$ HEPES (pH 7.4) containing $0.15 \mathrm{M} \mathrm{NaCl}, 3.4 \mathrm{mM}$ EDTA and $0.005 \%$ (v/v) Tween P20]. The human TRAIL-R2 (Enzo Life Sciences, Farmingdale, NY, USA) receptor was immobilized on a sCM5 sensor chip (GE Healthcare) using the standard amine coupling procedure. The receptors were diluted in $10 \mathrm{mM}$ acetate buffer $(\mathrm{pH} 5.0)$ at a concentration of $5 \mu \mathrm{g} / \mathrm{mL}$. The TRAIL-R2 immobilization level on the sensor chip was 430 RU. Peptides were injected at a flow rate of $5 \mu \mathrm{L} / \mathrm{min}$ for $120 \mathrm{~s}$ and allowed to dissociate for an additional $420 \mathrm{~s}$. Surfaces were then regenerated for $5 \mathrm{~s}$ with $25 \mathrm{mM} \mathrm{HCl}$. All binding curves were doublereferenced (i.e. subtraction of the data of the empty flow cell followed by the subtraction of the data from a running buffer injection cycle).

\section{Real time kinetic measurement assay on living cells}

The adherent cells HCT116-TRAIL-R2-DEF and HCT116 cells were directly plated on glass slides $(\varnothing 20 \mathrm{~mm})\left(10^{6}\right.$ cells/well $)$. The cells in suspension (BJAB and BJAB-TRAIL-R2-DEF) were covalently adhered to glass slides coated with poly-L-lysine $(0.1 \% \mathrm{v} / \mathrm{v})$ (Sigma Aldrich, Saint Louis, MO, USA). The adhesion was strong enough for measurement during $10 \mathrm{~h}$. After 24 hours, the slides were fixed with superglue at different locations of a Petri dish, which was inserted in the LigandTracer Green instrument [28, 29] (Ridgeview Instrument AB, Uppsala, Sweden). An empty spot or empty glass slide fixed to the Petri dish was used to record the background signal. This set-up allowed the simultaneous monitoring of the binding of a given peptide to different cell-carrying glass slides fixed to the dish. Three $\mathrm{mL}$ of solution (culture medium without or with fluorescent peptide) were added to the dish. In the LigandTracer instrument, the dish is tilted and rotates. Consequently the $3 \mathrm{~mL}$ solution covers only the lower part of the dish and each cell-carrying slide is alternatively in contact and out of contact with the solution (at intervals of 8 to $16 \mathrm{~s}$ ). The fluorescence signal is recorded over time when the slide is out of the solution, and therefore corresponds to the amount of bound peptide. The solution in the dish was initially the culture medium $(\sim 30 \mathrm{~min})$ to provide a stable base line. The fluorescent peptide was then added in increasing doses $(10,30$ and $90 \mathrm{nM})$ every two to three hours. Finally the peptide-containing sample was replaced with fresh medium and the dissociation of the peptide from the cells was followed overnight. The measurements were conducted at room temperature (approximately $20^{\circ} \mathrm{C}$ ).

\section{Evaluation of kinetic data}

Double-referenced SPR binding curves sets were fitted globally using the BIAevaluation 4.1.1 (GE Healthcare Biacore) or TraceDrawer (Ridgeview Diagnostics AB, Uppsala, Sweden) softwares. The signal recorded with the LigandTracer on an empty spot or slide was subtracted from that recorded on cell-carrying slides. The resulting binding curves were analyzed by kinetic distribution analysis [31] using the tool Interaction Map (Ridgeview Diagnostics AB, Uppsala, Sweden) [32,33]. Interaction Map decomposes the kinetic curve recorded for the binding of a homogeneous ligand to a heterogeneous group of targets into its different components. Results are represented as interaction maps $\left(\mathrm{k}_{\mathrm{on}}\right.$ versus $\mathrm{k}_{\text {off }} \log$ scale), where the color of each populated area represents its degree of contribution to the kinetic curve (red $=$ high contribution, blue $=$ low contribution) .

\section{Statistical analysis}

Results from cell viability experiments were expressed as the mean $\pm \mathrm{SEM}$. The statistical significance was evaluated by a non-parametric ANOVA 2 way test plus a Bonferonni correction using GrapPad Prism 5.0 software. Results with a $p$-value less than 0.05 were considered significant. 


\section{ACKNOWLEDGMENTS}

We thank: Dr Andrew Thorburn (Department of Pharmacology, University of Colorado Denver School of Medicine, USA) for kindly providing BJAB cell lines and Drs Karl Andersson and Hanna Björkelund (Ridgeview Instrument AB, Uppsala, Sweden) for helpful advice and discussions, Drs Sina Bondza and Magnus Malmqvist for critical reading of the manuscript.

\section{CONFLICTS OF INTEREST}

The authors declare no conflicts of interest.

\section{GRANT SUPPORT}

DA and SF gratefully acknowledge financial support from the "Centre National de la Recherche Scientifique", University of Strasbourg and "Agence Nationale de la Recherche" (ANR-08-PCVI-0034) and "Ligue Contre le Cancer Grand Est". NC was granted by the French "Ministère de la Recherche". DA acknowledges COST Action BM1003.

\section{REFERENCES}

1. Pan G, O'Rourke K, Chinnaiyan AM, Gentz R, Ebner R, Ni J, Dixit VM. The receptor for the cytotoxic ligand TRAIL. Science. 1997; 276:111-113.

2. Chaudhary PM, Eby M, Jasmin A, Bookwalter A, Murray J, Hood L. Death receptor 5, a new member of the TNFR family, and DR4 induce FADD-dependent apoptosis and activate the NF-kappaB pathway. Immunity. 1997; 7:821-830.

3. Walczak H, Degli-Esposti MA, Johnson RS, Smolak PJ, Waugh JY, Boiani N, Timour MS, Gerhart MJ, Schooley KA, Smith CA, Goodwin RG, Rauch CT. TRAIL-R2: a novel apoptosis-mediating receptor for TRAIL. EMBO J. 1997; 16:5386-5397.

4. Marsters SA, Sheridan JP, Pitti RM, Huang A, Skubatch M, Baldwin D, Yuan J, Gurney A, Goddard AD, Godowski P, Ashkenazi A. A novel receptor for Apo2L/TRAIL contains a truncated death domain. Curr Biol. 1997; 7:1003-1006.

5. Bodmer JL, Holler N, Reynard S, Vinciguerra $P$, Schneider P, Juo P, Blenis J, Tschopp J. TRAIL receptor-2 signals apoptosis through FADD and caspase-8. Nat Cell Biol. 2000; 2:241-243.

6. Yang A, Wilson NS, Ashkenazi A. Proapoptotic DR4 and DR5 signaling in cancer cells: toward clinical translation. Curr Opin Cell Biol. 2010; 22:837-844.

7. Shirley S, Morizot A, Micheau O. Regulating TRAIL receptor-induced cell death at the membrane : a deadly discussion. Recent Patents Anticancer Drug Discov. 2011; 6:311-323.

8. Lamanna G, Smulski CR, Chekkat N, Estieu-Gionnet K, Guichard G, Fournel S, Bianco A. Multimerization of an apoptogenic TRAIL-mimicking peptide by using adamantane-based dendrons. Chemistry. 2013; 19: $1762-1768$.

9. Wajant H, Moosmayer D, Wuest T, Bartke T, Gerlach E, Schonherr U, Peters N, Scheurich P, Pfizenmaier K. Differential activation of TRAIL-R1 and -2 by soluble and membrane TRAIL allows selective surface antigen-directed activation of TRAIL-R2 by a soluble TRAIL derivative. Oncogene. 2001; 20:4101-4106.

10. Chan FK. Three is better than one: pre-ligand receptor assembly in the regulation of TNF receptor signaling. Cytokine. 2007; 37:101-107.

11. Valley CC, Lewis AK, Mudaliar DJ, Perlmutter JD, Braun AR, Karim CB, Thomas DD, Brody JR, Sachs JN. Tumor necrosis factor-related apoptosis-inducing ligand (TRAIL) induces death receptor 5 networks that are highly organized. J Biol Chem. 2012; 287:21265-21278.

12. Szegezdi E, van der Sloot AM, Mahalingam D, O'Leary L, Cool RH, Munoz IG, Montoya G, Quax WJ, de Jong S, Samali A, Serrano L. Kinetics in signal transduction pathways involving promiscuous oligomerizing receptors can be determined by receptor specificity: apoptosis induction by TRAIL. Mol Cell Proteomics. 2012; 11:M111.013730.

13. Hymowitz SG, Christinger HW, Fuh G, Ultsch M, O'Connell M, Kelley RF, Ashkenazi A, de Vos AM. Triggering cell death: the crystal structure of Apo2L/TRAIL in a complex with death receptor 5. Mol Cell. 1999; 4:563-571.

14. Nesterov A, Nikrad M, Johnson T, Kraft AS. Oncogenic Ras sensitizes normal human cells to tumor necrosis factoralpha-related apoptosis-inducing ligand-induced apoptosis. Cancer Res. 2004; 64:3922-3927.

15. Lemke J, von Karstedt S, Zinngrebe J, Walczak H. Getting TRAIL back on track for cancer therapy. Cell Death Differ. 2014; 21:1350-1364.

16. Dimberg LY, Anderson CK, Camidge R, Behbakht K, Thorburn A, Ford HL. On the TRAIL to successful cancer therapy? Predicting and counteracting resistance against TRAIL-based therapeutics. Oncogene. 2013; 32:1341-1350.

17. Stuckey DW, Shah K. TRAIL on trial: preclinical advances in cancer therapy. Trends Mol Med. 2013; 19:685-694.

18. Micheau O, Shirley S, Dufour F. Death receptors as targets in cancer. Br J Pharmacol. 2013; 169:1723-1744.

19. Trivedi R, Mishra DP. Trailing TRAIL Resistance: Novel Targets for TRAIL Sensitization in Cancer Cells. Front Oncol. 2015; 5:69.

20. Buneker C, Mohr A, Zwacka RM. The TRAIL-receptor-1: TRAIL-receptor-3 and -4 ratio is a predictor for TRAIL sensitivity of cancer cells. Oncol Rep. 2009; 21:1289-1295.

21. Sanlioglu AD, Dirice E, Aydin C, Erin N, Koksoy S, Sanlioglu S. Surface TRAIL decoy receptor-4 expression is correlated with TRAIL resistance in MCF7 breast cancer cells. BMC Cancer. 2005; 5:54.

22. Kohlhaas SL, Craxton A, Sun XM, Pinkoski MJ, Cohen GM. Receptor-mediated endocytosis is not required for tumor 
necrosis factor-related apoptosis-inducing ligand (TRAIL)induced apoptosis. J Biol Chem. 2007; 282:12831-12841.

23. Clancy L, Mruk K, Archer K, Woelfel M, Mongkolsapaya J, Screaton G, Lenardo MJ, Chan FK. Preligand assembly domain-mediated ligand-independent association between TRAIL receptor 4 (TR4) and TR2 regulates TRAILinduced apoptosis. Proc Natl Acad Sci USA. 2005; 102:18099-18104.

24. Merino D, Lalaoui N, Morizot A, Schneider P, Solary E, Micheau O. Differential inhibition of TRAIL-mediated DR5-DISC formation by decoy receptors 1 and 2. Mol Cell Biol. 2006; 26:7046-7055.

25. Haynes NM, Hawkins ED, Li M, McLaughlin NM, Hammerling GJ, Schwendener R, Winoto A, Wensky A, Yagita H, Takeda K, Kershaw MH, Darcy PK, Smyth MJ. $\mathrm{CD} 11 \mathrm{c}+$ dendritic cells and $\mathrm{B}$ cells contribute to the tumoricidal activity of anti-DR5 antibody therapy in established tumors. J Immunol. 2010; 185:532-541.

26. Wilson NS, Yang B, Yang A, Loeser S, Marsters S, Lawrence D, Li Y, Pitti R, Totpal K, Yee S, Ross S, Vernes JM, Lu Y, et al. An Fc $\gamma$ receptor-dependent mechanism drives antibodymediated target-receptor signaling in cancer cells. Cancer Cell. 2011; 19:101-13.

27. Beyrath J, Chekkat N, Smulski CR, Lombardo CM, Lechner MC, Seguin C, Decossas M, Spanedda MV, Frisch B, Guichard G, Fournel S. Synthetic ligands of death receptor 5 display a cell-selective agonistic effect at different oligomerization levels. Oncotarget. 2016; 7:64942-56. https://doi.org/10.18632/oncotarget.10508.

28. Pavet V, Beyrath J, Pardin C, Morizot A, Lechner MC, Briand JP, Wendland M, Maison W, Fournel S, Micheau O, Guichard G, Gronemeyer H. Multivalent DR5 peptides activate the TRAIL death pathway and exert tumoricidal activity. Cancer Res. 2010; 70:1101-1110.

29. Björke H, Andersson K. Measuring the affinity of a radioligand with its receptor using a rotating cell dish with in situ reference area. Appl Radiat Isot. 2006; 64:32-7.

30. Bjorke H, Andersson K. Automated, high-resolution cellular retention and uptake studies in vitro. Appl Radiat Isot. 2006; 64:901-905.

31. Altschuh D, Bjorkelund H, Strandgard J, Choulier L, Malmqvist M, Andersson K. Deciphering complex protein interaction kinetics using Interaction Map. Biochem Biophys Res Commun. 2012; 428:74-79.

32. Svitel J, Balbo A, Mariuzza RA, Gonzales NR, Schuck P. Combined affinity and rate constant distributions of ligand populations from experimental surface binding kinetics and equilibria. Biophys J. 2003; 84:4062-4077.

33. Barta P, Malmberg J, Melicharova L, Strandgard J, Orlova A, Tolmachev V, Laznicek M, Andersson K. Protein interactions with HER-family receptors can have different characteristics depending on the hosting cell line. Int J Oncol. 2012; 40:1677-1682.

34. Bjorkelund $\mathrm{H}$, Gedda L, Barta $\mathrm{P}$, Malmqvist $\mathrm{M}$, Andersson K. Gefitinib induces epidermal growth factor receptor dimers which alters the interaction characteristics with ${ }^{125}$ I-EGF. PLoS One. 2011; 6:e24739.

35. Smulski CR, Beyrath J, Decossas M, Chekkat N, Wolff P, Estieu-Gionnet K, Guichard G, Speiser D, Schneider P, Fournel S. Cysteine-rich domain 1 of CD40 mediates receptor self-assembly. J Biol Chem. 2013; 288:10914-22.

36. Nordberg E, Steffen AC, Persson M, Sundberg AL, Carlsson J, Glimelius B. Cellular uptake of radioiodine delivered by trastuzumab can be modified by the addition of epidermal growth factor. Eur J Nucl Med Mol Imaging. 2005; 32:771-777.

37. Wei Q, Kullberg EB, Gedda L. Trastuzumab-conjugated boron-containing liposomes for tumor-cell targeting; development and cellular studies. Int J Oncol. 2003; 23:1159-1165.

38. Barta P, Volkova M, Dascalu A, Spiegelberg D, Trejtnar F, Andersson K. Determination of receptor protein binding site specificity and relative binding strength using a timeresolved competition assay. J Pharmacol Toxicol Methods. 2014; 70:145-151.

39. Bjorkelund H, Gedda L, Malmqvist M, Andersson K. Resolving the EGF-EGFR interaction characteristics through a multipletemperature, multiple-inhibitor, real-time interaction analysis approach. Mol Clin Oncol. 2013; 1:343-352.

40. Stenberg J, Spiegelberg D, Karlsson H, Nestor M. Choice of labeling and cell line influences interactions between the Fab fragment AbD15179 and its target antigen CD44v6. Nucl Med Biol. 2014; 41:140-147.

41. Patsos G, Andre S, Roeckel N, Gromes R, Gebert J, Kopitz J, Gabius HJ. Compensation of loss of protein function in microsatellite-unstable colon cancer cells (HCT116): a gene-dependent effect on the cell surface glycan profile. Glycobiology. 2009; 19:726-734.

42. Pulka-Ziach K, Pavet V, Chekkat N, Estieu-Gionnet K, Rohac R, Lechner MC, Smulski CR, Zeder-Lutz G, Altschuh D, Gronemeyer H, Fournel S, Odaert B, Guichard G. Thioether analogues of disulfide-bridged cyclic peptides targeting death receptor 5: conformational analysis, dimerisation and consequences for receptor activation. ChemBioChem. 2015; 16:293-301.

43. Thomas LR, Johnson RL, Reed JC, Thorburn A. The C-terminal tails of tumor necrosis factor-related apoptosis-inducing ligand (TRAIL) and Fas receptors have opposing functions in Fas-associated death domain (FADD) recruitment and can regulate agonist-specific mechanisms of receptor activation. J Biol Chem. 2004; 279:52479-52486.

44. Dufour F, Rattier T, Constantinescu AA, Zischler L, Morlé A, Ben Mabrouk H, Humblin E, Jacquemin G, Szegezdi E, Delacote F, Marrakchi N, Guichard G, Pellat-Deceunynck C, et al. TRAIL receptor gene editing unveils TRAIL-R1 as a master player of apoptosis induced by TRAIL and ER stress. Oncotarget. 2017; 8:9974-85. https://doi.org/10.18632/ oncotarget.14285. 